\title{
Molecular Profiling of Hepatocellular Carcinoma in Mice with a Chronic Deficiency of Hepatic S-Adenosylmethionine: Relevance in Human Liver Diseases
}

\author{
Enrique Santamaría, ${ }^{\dagger, \perp}$ Javier Muñoz, ${ }^{\dagger, \perp}$ Joaquín Fernández-Irigoyen, ${ }^{\dagger}$ Laura Sesma, ${ }^{\dagger}$

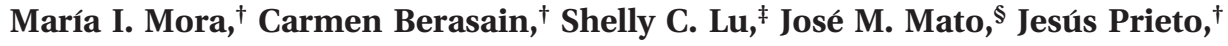 \\ Matías A. Avila, ${ }^{\dagger, \|}$ and Fernando J. Corrales ${ }^{*,+, \|}$ \\ Division of Hepatology and Gene Therapy, CIMA, University of Navarra, 31008 Pamplona, Spain, Division of \\ Gastroenterology and Liver Diseases, University of Souther California Research Center for Liver Diseases, \\ University of Southern California-University of California at Los Angeles Research Center for Alcoholic Liver \\ and Pancreatic Diseases, Keck School of Medicine of the University of Southern California, Los Angeles, \\ California 90033, and CIC-Biogune, Metabolomics Unit, Technological Park of Bizkaia, 48710 Zamudio, Spain
}

Received November 30, 2005

\begin{abstract}
$S$-adenosylmethionine arises as a central molecule in the preservation of liver homeostasis as a chronic hepatic deficiency results in spontaneous development of steatohepatitis and hepatocellular carcinoma. In the present work, we have attempted a comprehensive analysis of proteins associated with hepatocarcinogenesis in MAT1A knock out mice using a combination of two-dimensional electrophoresis and mass spectrometry, to then apply the resulting information to identify hallmarks of human HCC. Our results suggest the existence of individual-specific factors that might condition the development of preneoplastic lesions. Proteomic analysis allowed the identification of 151 differential proteins in MAT1A-/- mice tumors. Among all differential proteins, 27 changed in at least $50 \%$ of the analyzed tumors, and some of these alterations were already detected months before the development of HCC in the KO liver. The expression level of genes coding for 13 of these proteins was markedly decreased in human HCC. Interestingly, seven of these genes were also found to be down-regulated in a pretumoral condition such as cirrhosis, while depletion of only one marker was assessed in less severe liver disorders.
\end{abstract}

Keywords: S-adenosylmethionine $\cdot$ hepatocellular carcinoma • two-dimensional gel electrophoresis $\bullet$ mass spectrometry $\bullet$ proteomics $\bullet$ biomarkers

\section{Introduction}

Since its discovery in 1953 by Cantoni, ${ }^{1,2}$ an increasing number of studies provide evidences supporting the central function of $S$-adenosylmethionine (AdoMet) in cell biology. Along with ATP, AdoMet is one of the metabolites most frequently used in intermediary metabolism. It is the main alkylating agent in living cells participating in the methylation of nucleic acids, proteins, phospholipids, hormones, xenobiotics, and other molecules through the transference of its methyl group to the acceptors in reactions catalyzed by methyltransferases. Additionally, AdoMet is involved in the

* To whom correspondence should be addressed. Tel: 34-948-194700. Fax: 34-948-194718. E-mail address: fjcorrales@unav.es.

${ }^{\dagger}$ Division of Hepatology and Gene Therapy, CIMA, University of Navarra.

‡ Division of Gastroenterology and Liver Diseases, University of Souther California Research Center for Liver Diseases, University of Southern California-University of California at Los Angeles Research Center for Alcoholic Liver and Pancreatic Diseases, Keck School of Medicine of the University of Southern California.

${ }^{\S}$ CIC-Biogune, Metabolomics Unit, Technological Park of Bizkaia.

" These authors share senior authorship.

${ }^{\perp}$ Authors contributed equally to this work. biosynthesis of different metabolites such us polyamines, biotin, and, in the liver, is an intermediary metabolite in the synthesis of cysteine and glutathione ${ }^{2-4}$ Methionine adenosyltransferase (MAT) catalyzes the only known AdoMet biosynthetic reaction using methionine and ATP as substrates. ${ }^{1,5}$ In mammalian tissues two distinct genes, MAT1A and MAT2A, ${ }^{6-9}$ encode three different MAT isoforms. ${ }^{9-12}$ MAT2A encodes a 396 -amino acid $\alpha 2$ catalytic subunit that forms the tetrameric MATII. ${ }^{5,13}$ MAT1A encodes a 395-amino acid $\alpha 1$ subunit that organizes into dimers, MATIII, and tetramers, MATI. , $10,14-16^{2}$ The three MAT species catalyze the same reaction but their tissue distribution, kinetics, and regulation are different. ${ }^{17}$ The expression of MAT1A is restricted to liver and pancreas, ${ }^{18}$ while MAT2A is mainly expressed in extrahepatic tissues and also predominates in the fetal liver where is progressively replaced by MAT1A during development. ${ }^{19,20}$ Hepatic MAT activity and expression are impaired in pathological conditions such as human cirrhosis and in a variety of experimental models including liver injury induced by ethanol, $\mathrm{CCl}_{4}$, galactosamine, bacterial lipopolysaccharide, and hypoxia. ${ }^{5,13,21}$ The importance of this alteration in AdoMet synthesis in the pathogenesis of 
liver disorders is supported by the finding that exogenous AdoMet administration protects from the hepatotoxic effects of these agents ${ }^{5,13}$ and increases survival in patients with alcoholic liver cirrhosis. ${ }^{22}$ In adult liver, increased expression of MAT2A and MAT1A silencing is associated with rapid growth or de-differentiation of the liver, as during liver regeneration induced by partial hepatectomy ${ }^{23,24}$ and in hepatocarcinogenesis. ${ }^{25-27}$ The cellular content of AdoMet seems to be related to the differentiation status of the hepatocyte. ${ }^{17}$ In this regard, quiescent hepatocytes display higher AdoMet content that proliferating hepatocytes ${ }^{17}$ resulting from a switch in gene expression from MAT1A to MAT2A. ${ }^{23-27}$ Previous work shows that AdoMet helps to turn off the hepatocyte responses to growth factors, and that without this protection, the uncontrolled progression of cancer takes place. ${ }^{24}$ Thus, KO mice deficient in AdoMet synthesis (MAT1A-/-) spontaneously develop oxidative stress, non alcoholic steatohepatitis (NASH), and hepatocellular carcinoma (HCC) by 8 and 18 months of age respectively. ${ }^{28-30}$

Primary liver cancer is the fifth most frequent neoplasm and the third most common cause of cancer related death with more than 500000 new cases diagnosed yearly. ${ }^{31}$ Hepatocellular carcinoma (HCC) is a major health problem in Asia and Africa with an incidence steadily increasing in western countries. ${ }^{31}$ Major causes of HCC are currently known, including infection with hepatitis $\mathrm{B}(\mathrm{HBV})$ and $\mathrm{C}$ (HCV) viruses, ingestion of aflatoxin contaminated food and alcohol abuse. ${ }^{32}$ Other less prevalent risk factors have also been described such as iron or cooper deposition or nonalcoholic steatohepatitis (NASH). ${ }^{33}$ Although the identification of the main risk factors and the routine screening of population at risk may lead to the early diagnosis of HCC, the prognosis of these patients is poor mainly due to the aggressiveness of the lesions at the time of diagnosis and to the lack of effective therapies. Therefore, the improvement of our knowledge about the molecular pathogenesis of HCC and the identification of biomarkers leading to an early diagnosis are of great interest and one of the priorities of clinical hepatology. At present, only five biomarkers for HCC are available for clinical use ${ }^{34}$ from which only alpha fetoprotein partially fulfils the requirements of an ideal tumor marker. ${ }^{34}$ The recent technological advances in genomics and proteomics greatly promoted the systematic analysis of global gene expression and protein abundance profiles of normal and diseased tissue, providing new insights into the pathogenic mechanisms of human diseases ${ }^{35-37}$ as well as disease-associated targets.

In the present work, we have attempted a comprehensive analysis of proteins associated with hepatocarcinogenesis in MAT1A-/- mice using a combination of two-dimensional electrophoresis (2-DE) and mass spectrometry to then apply the resulting information to identify hallmarks of human HCC. Our results provide evidences suggesting that stochastic alterations associated with tumor growth as well as the selective pressure imposed by individual-specific factors on preneoplastic foci contribute to increase proteome heterogeneity between tumor nodules. Among 151 differential proteins identified in the mouse model, we found a cluster of 15 proteins that may prove to be useful in the early diagnosis of human HCC.

\section{Experimental Section}

Materials. Electrophoresis reagents were from Bio-Rad, trypsin was from Promega, urea was from USB. Ethanol and trifluoroacetic acid were from Merck. All other reagents were from Sigma. Animals were from our inbred colony and were treated humanely, according to our institution's guidelines. We obtained liver samples from 5 groups of subjects (age range 40-80): (a) Control individuals $(n=12)$; (b) patients with alcoholic liver cirrhosis $(n=5)$; (c) patients with viral liver cirrhosis $(n=10)$; (d) patients with primary HCC $(n=10)$; (e) peritumoral liver samples from patients with primary HCC without liver cirrhosis $(n=10)$. HCC patients were not receiving any preoperative therapy such as chemotherapy, percutaneous ethanol injection, or transcatheter arterial embolization. Control human liver tissue was obtained from patients in whom a cholecystectomy was performed for the treatment of a sympthomatic cholelithiasis and who consented to be submitted to a liver biopsy during the surgical procedure. In the control group, both the liver function tests and liver histology were normal or showed minimal changes. Cirrhotic liver samples were obtained at the time of transplantation, and cancerous tissue during surgical resection. This study was approved by the human research review committee of the University of Navarra. Studies were conducted in compliance with the ethical standards formulated at the Helsinki Declaration of 1996 (revised in 2000).

Methods. Protein Separation by Two-Dimensional Electrophoresis. Liver tumors were measured, resected and immediately freeze clamped in liquid nitrogen. Samples were then stored at $-80{ }^{\circ} \mathrm{C}$ until use. Before proteomic analysis, sections from formalin fixed tissue were stained with hematoxylin and eosin and examined by two pathologists unaware of the animals' identity. In all cases, MAT1A-/- liver tumors are composed of hepatocytes having round-to-oval nuclei and prominent nucleoli, forming thickened trabecular cords lined by endothelial cells. Tumor specimens were homogenized in 20 volumes of lysis buffer containing $7 \mathrm{M}$ urea, $2 \mathrm{M}$ thiourea, $4 \%$ (v/v) CHAPS, $1 \%$ (v/v) DTT and $0.5 \%$ Bio-Lyte 3-10 ampholytes. Homogenates were spinned down at $100000 \times g$ for $45 \mathrm{~min}$ at $15{ }^{\circ} \mathrm{C}$. Protein concentration was measured in the supernatant with the Bradford assay kit (BioRad), using bovin serum albumin as standard protein. Protein separation by two-dimensional electrophoresis (2DE) was performed as described previously. ${ }^{30}$ Analytical gels (total protein amount was $150 \mu \mathrm{g}$ ) were stained with Sypro Ruby. Preparative gels (total protein amount was $800 \mu \mathrm{g}$ ) were visualized with Coomassie Safe Stain (Invitrogen). Gel scanning was performed with a Molecular Imager FX and a densitometer GS800 (BioRad). Images were processed with the PDQuest 7.1 analysis software. To diminish the inherent variability associated with 2DE analysis, the optical density of each spot was normalized using the optical density calculated for all matched spots. All samples were analyzed in triplicate. Quantitative differences were only accepted when at least a 3 -fold change was confirmed in all three independent experiments. Spots differentially represented were excised manually and gel specimens were processed with a MassPrep station (Waters) as described elsewhere. ${ }^{30}$ In-gel tryptic digestion was performed with $6 \mathrm{ng} / \mu \mathrm{L}$ trypsin in $50 \mathrm{mM}$ ammonium bicarbonate for $5 \mathrm{~h}$ at $37^{\circ} \mathrm{C}$. The resulting peptides were extracted with $1 \%$ formic acid, $2 \%$ acetonitrile.

Protein Identification by Mass Spectrometry. Peptide mass fingerprints (PMF) were obtained from the tryptic digests using a MALDI-TOF GL-REF mass spectrometer from Waters. Briefly, $1.2 \mu \mathrm{L}$ of the tryptic digest were mixed with an equal volume of $\alpha$-cyano- 4 -hydroxy-trans-cynnamic acid in $0.1 \%$ TFA in $50 \%$ acetonitrile and spotted onto a MALDI-TOF target plate. The system was calibrated daily with a tryptic digest of $\mathrm{ADH}$. Data 
Table 1. Designed Primers Used in RT-PCR and Real Time PCR

ornithine aminotransferase
malate dehydrogenase
antioxidant protein 2
aldehyde dehydrogenase mit.
glycine $N$-methyltransferase
sorbitol dehydrogenase
apolipoprotein E
serum albumin
apolipoprotein A1
glutathione S-transferase P2
methionine adenosyltransferase I
carbonic anhidrase III
protein disulfide isomerase
adenosylhomocysteinase
heat shock cognate 71 kDa
nonspecific lipid transfer prot.
phenylalanine 4 -hydroxilase
alcohol dehydrogenase
arginase 1
selenium binding protein
glutamine synthase
phosphoglucomutase
senescence marker protein 30
ornithine carbamoyltransferase
glutathione S-transferase mu1

ornithine aminotransferase

malate dehydrogenase

aldehyde dehydrogenase mit.

glycine $N$-methyltransferas

apolipoprotein $\mathrm{E}$

glutathione S-transferase P2

methionine adenosyltransferase I

protein disulfide isomerase

adenosylhomocysteinase

phenylalanine 4-hydroxilase

alcohol dehydrogenase

glutamine synthase

senescence marker protein 30

ornithine carbamoyltransferase
glutathione S-transferase mul

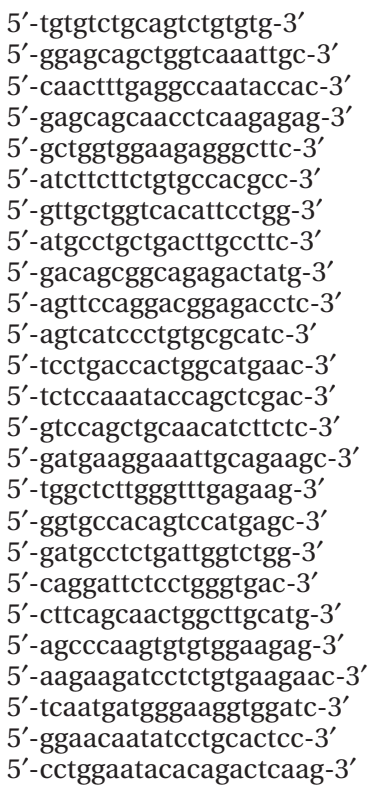

$5^{\prime}$-tgtgtctgcagtctgtgtg-3'

$5^{\prime}$-ggagcagctggtcaaattgc- $3^{\prime}$

$5^{\prime}$-caactttgaggccaataccac- $3^{\prime}$

$5^{\prime}$-gagcagcaacctcaagagag- $3^{\prime}$

$5^{\prime}$-gctggtggaagagggcttc- $3^{\prime}$

$5^{\prime}$-atcttcttctgtgccacgcc- $3^{\prime}$

$5^{\prime}$-gttgctggtcacattcctgg- $3^{\prime}$

$5^{\prime}$-atgcctgctgacttgccttc- $3^{\prime}$

$5^{\prime}$-gacagcggcagagactatg- $3^{\prime}$

$5^{\prime}$-agttccaggacggagacctc- $3^{\prime \prime}$

$5^{\prime}$-agtcatccctgtgcgcatc- $3^{\prime}$

$5^{\prime}$-tcctgaccactggcatgaac- 3

(ctccaaataccagctcgac- $3^{\prime \prime}$

5'-gactcte-3

$5^{\prime}$-tggctcttgggtttgagaag- $3^{\prime}$

$5^{\prime}$-ggtgccacagtccatgagc- $3^{\prime}$

$5^{\prime}$-gatgcctctgattggtctgg- $3^{\prime}$

$5^{\prime}$-caggattctcctgggtgac- $3^{\prime}$

cttcagcaactggcttgcatg-

$5^{\prime}$-aagaagatcctctgtgaagaac- $3^{\prime}$

5 -tcaatgatgggaaggtggatc- 3

$5^{\prime}$-cctggaatacacagactcaag-3
$5^{\prime}$-agacacaccttccaagcatc- $3^{\prime}$
$5^{\prime}$-tccatgccttcccttcttgg-3'
$5^{\prime}$-tccttgctccaggcaagatg- $3^{\prime}$
$5^{\prime}$-cgaggatcttcttaaactgag- $3^{\prime}$
$5^{\prime}$-cctttgcagtctggcaagtg- $3^{\prime}$
$5^{\prime}$-gctcccattgctttggecac-3'
$5^{\prime}$-taggccttcaactccttcatg- $3^{\prime}$
$5^{\prime}$-ctgaggctcttccacaagag- $3^{\prime}$
$5^{\prime}$-ccaccttctggcggtagag- $3^{\prime}$
$5^{\prime}$-cagggtctcaaaaggcttcag- $3^{\prime}$
$5^{\prime}$-ggtccaccttggtgtagtc- $3^{\prime}$
$5^{\prime}$ - tgctcagagccatgatcatc- $3^{\prime}$
$5^{\prime}$-caggatcttgcccttgaagc- $3^{\prime}$
$5^{\prime}$-cagtcgtggtctcctcagag- $3^{\prime}$
$5^{\prime}$-caatagtgaggattgacacatc- $3^{\prime}$
$5^{\prime}$-catcttggaactgggaatacg- $3^{\prime}$
$5^{\prime}$-ggcggtagttgtaggcaatg- $3^{\prime}$
$5^{\prime}$-cttggatgtcacaaacagctc- $3^{\prime}$
$5^{\prime}$-gatgtagagaccttctctg- $3^{\prime}$
$5^{\prime}$-gctgagctggatcatctgag- $3^{\prime}$
$5^{\prime}$-tgctggttgctcaccatgtc- $3^{\prime}$
$5^{\prime}$-gaatgctgaagatgttggcag- $3^{\prime}$
$5^{\prime}$-agggtcatagtcaaaggcatcc- $3^{\prime}$
$5^{\prime}$-ctgtaattaatacattgcctcc- $3^{\prime}$
$5^{\prime}$-tcttctcctcttctgtctcc-3

processing was performed with Masslynx 4.0 (Waters) using ACTH as internal lock-mass standard.

Microcapillary reversed phase LC was performed with a CapLC (Waters) capillary system. Reversed-phase separation of tryptic digests was performed with an Atlantis, $\mathrm{C}_{18}, 3 \mu \mathrm{m}, 75$ $\mu \mathrm{m} \times 10 \mathrm{~cm}$ Nano Ease fused silica capillary column (Waters) equilibrated in $5 \%$ acetonitrile, $0.2 \%$ formic acid. After injection of $6 \mu \mathrm{L}$ of sample, the column was washed during 5 min with the same buffer and the peptides were eluted using a linear gradient of $5-50 \%$ acetonitrile in $30 \mathrm{~min}$ at a constant flow rate of $0.2 \mu \mathrm{L} / \mathrm{min}$. The column was coupled online to a $\mathrm{Q}-\mathrm{TOF}$ Micro (Waters) using a PicoTip nanospray ionization source (Waters). The heated capillary temperature was $80^{\circ} \mathrm{C}$ and the spray voltage was $1.8-2.2 \mathrm{kV}$. MS/MS data were collected in an automated data-dependent mode. The three most intense ions in each survey scan were sequentially fragmented by collision induced dissociation (CID) using an isolation width of 2.5 and a relative collision energy of $35 \%$. Data processing was performed with Masslynx 4.0.

Database searching was done with Proteinlynx Global Server 2.0 (Waters). Database used in this study were Swiss-Prot (release 46.3) and Ensembl Mouse (release 29.33) containing 176469 and 31535 sequence entries, respectively. Data analysis and protein clustering were done with GARBAN II (http:// garban.tecnun.es/garban2/index.php). ${ }^{38}$ This bioinformatic tool is implemented with applications that allow gene and protein classification according to Gene Ontology criteria. ${ }^{39}$

Protein identification was performed automatically but all individual spectra were subsequently inspected manually to ensure the certainty of the result. Protein identifications based on PMF were only accepted when the Masslynx score was at least 7 and the matched peptides represent at least $30 \%$ of the proposed protein sequence. Protein identifications from MS/MS data were only considered for score values above 7 and when were based on the sequence of at least 3 independent peptides.

RNA Isolation, RT-PCR and Real-Time PCR. Total RNA was extracted using TRI reagent (Sigma). RNA was treated ( $2 \mu \mathrm{g}$ ) with DNaseI (Invitrogen) prior to reverse transcription with M-MLV Reverse Transcriptase (Invitrogen) in the presence of
RNaseOUT (Invitrogen). Primers were designed to amplify specifically cDNA and all PCR products were sequenced to confirm the specificity. Real-time PCR was performed with 1/20 of the PCR reaction using an iCycler (BioRad) and the iQ SYBR Green Supermix (BioRad). The primers used are shown in Table 1. mRNA levels were normalized according to histone H3F3A quantitation in the same sample. The primers used for histone H3F3A amplification were as follows: $5^{\prime}$-aaagccgctcgcaagagtgcg-3' and 5'-acttgcctcctgcaaagcac-3'. To monitor the specificity, final PCR products were analyzed by melting curves and electrophoresis. The amount of transcripts was calculated and expressed as the relative difference to the control gene histone H3F3A $\left(2^{\Delta \mathrm{Ct}}\right.$, where $\Delta \mathrm{Ct}$ represents the difference in threshold cycles between the target and control genes), essentially as described elsewhere. ${ }^{40}$ RNA from five control individuals and milliQ water were used as positive and negative controls for the real-time PCR analyses.

Statistical Analysis. Data are given as mean \pm SD. For changes in mRNA levels between controls and liver diseased patients a global analysis including all experimental conditions was performed using a Kruskall Wallis test. The test indicated significant differences between groups. Paired analysis was then performed with the Mann-Withney test considering the correction of Bonferoni. The threshold for significance was an expected false discovery rate less than 0.05 .

\section{Results}

Proteomic Analysis of HCC in MAT1A-/- Mouse. The identification of proteins associated with HCC in MAT1A-/mice was performed by differential proteomics comparing 2-DE patterns of normal and tumoral tissue from 18 month old WT and KO mice respectively (Figure 1). Initially, five different WT liver samples and $\mathrm{KO}$ tumors were analyzed in triplicate to determine the degree of proteome variability in each group and to ensure the reproducibility of the method. On the basis of the results of the image analysis with PD Quest (BioRad), an average of 800 to 1200 spots were visualized depending on the amount of protein processed and the gel staining procedure. Comparison of 2-DE profiles from normal liver revealed an 


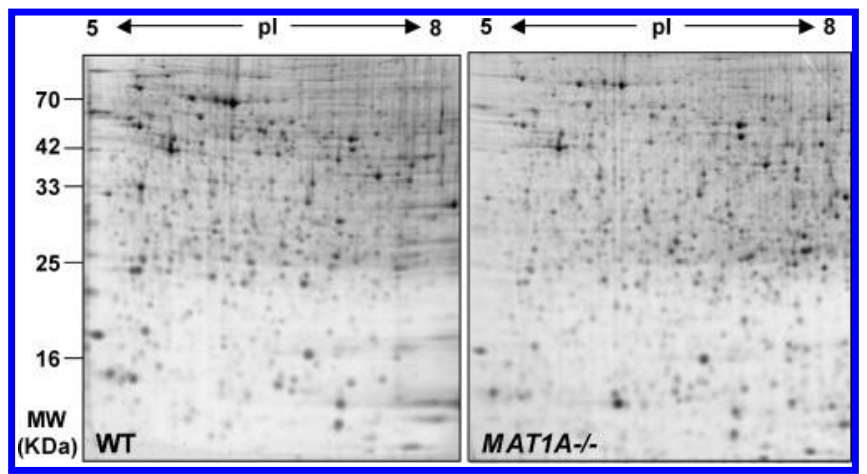

Figure 1. Representative analytical 2D gels from WT liver and MAT1A-/- liver tumor.

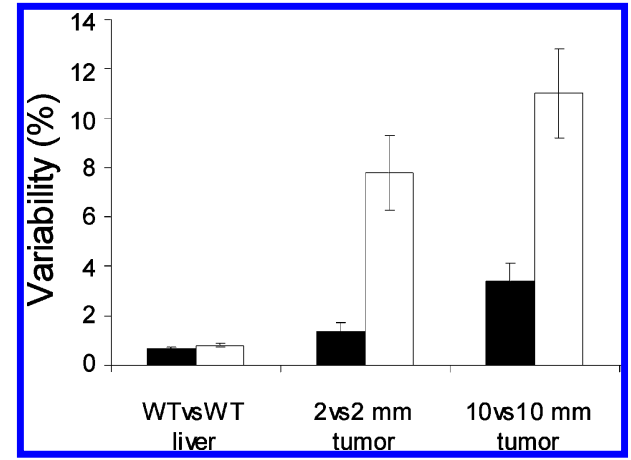

Figure 2. Proteome heterogeneity in liver tumors of MAT1A-/mice. Variability values (defined as the ratio differential spots/ analyzed spots $\times 100$ ) between the 2-DE profiles from normal liver and tumors were analyzed. Gel maps from 2 and $10 \mathrm{~mm}$ neoplastic lesions from the same or different animals were compared. Tumor excised from the same liver (black) showed a positive correlation between tumor size and variability. The analysis of tumors from different mice (white) showed variability values 10 -fold higher than those found in the WT group.

intra-group variability values (defined as the ratio differential spots/analyzed spots $\times 100$ ) lower than $1 \%$, similar to those measured in previous studies of MAT1A-/ - livers under different pathological conditions. However, variability increased significantly after HCC development, as manifested by comparison of tumor 2-DE maps (Figure 2). To investigate the origin of this proteome heterogeneity, gel maps from $2 \mathrm{~mm}$ and $10 \mathrm{~mm}$ neoplastic lesions from the same or different animals were compared. As expected, the examination of tumors excised from the same liver showed a positive correlation between tumor size and variability $(1.38 \pm 0.34 \%$ and $3.4 \pm 0.73 \%$ for 2 $\mathrm{mm}$ and $10 \mathrm{~mm}$ tumors respectively), in agreement with previous hypothesis suggesting a stochastic accumulation of proteomic changes in parallel with tumor growth. However, the analysis of tumors from different mice showed variability values 10 -fold higher $(7.8 \pm 1.51 \%$ and $11 \pm 1.79 \%$ for $2 \mathrm{~mm}$ and $10 \mathrm{~mm}$ tumors respectively) than those in the WT group $(0.8 \pm 0.08 \%)$ (Figure 2). These observations suggest that, in addition to tumor growth, individual-specific factors might contribute to proteome heterogeneity in HCC by imposing a selective pressure on preneoplastic foci. To identify the differential proteins associated with HCC in MAT1A-/- mice, tumor extracts from 6 different animals were processed in triplicate using preparative 2-DE (800 $\mu$ g protein). Each gel image was compared with WT maps to identify the differential spots of individual tumors, and changes were only accepted

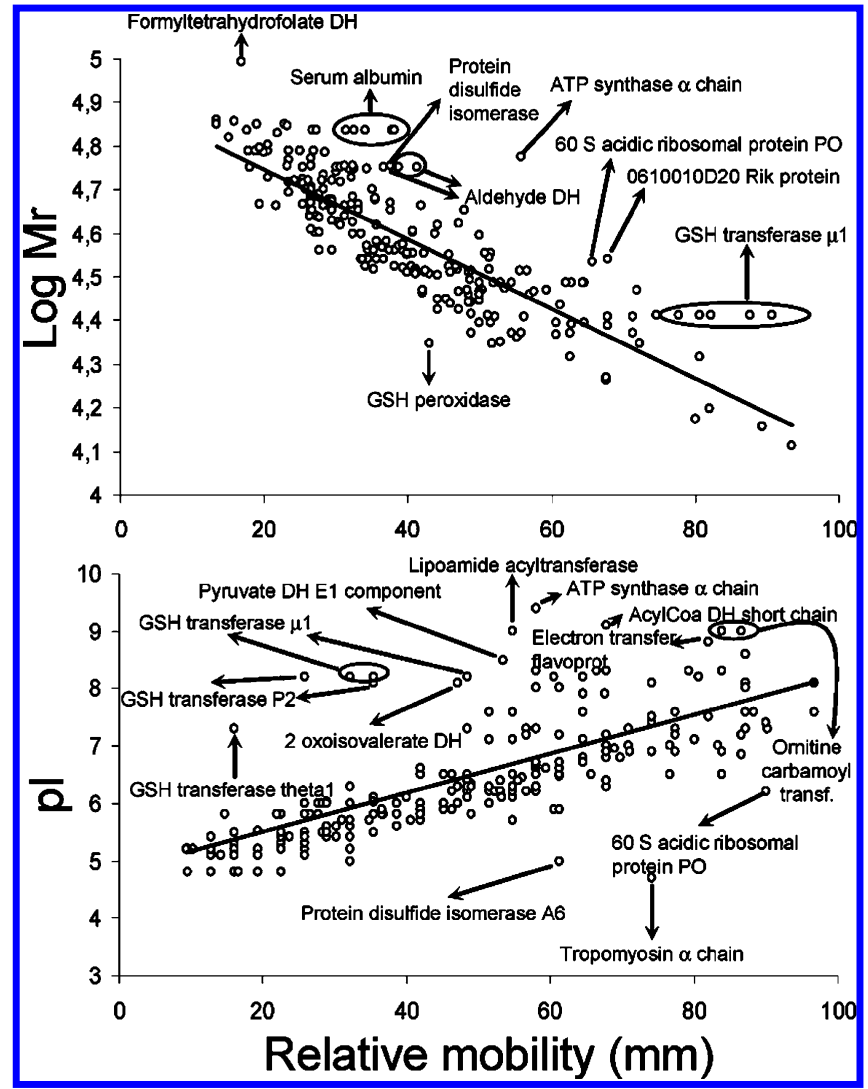

Figure 3. Correlation between the theoretical $M_{\mathrm{r}}$ and $\mathrm{p} /$ and the experimental relative mobility of differential proteins on 2DE. Most of the analyzed proteins, showed a linear correlation between the $M_{\mathrm{r}}$ (upper panel) and $\mathrm{p} /$ (lower panel) calculated from the sequence of the identified proteins and experimental electrophoretic mobility of the corresponding spot, calculated from the 2-DE gels. Protein species with anomalous $\mathrm{p} /$ and/or $M_{\mathrm{r}}$ are indicated.

when at least 3-fold increase or decrease was confirmed in the three independent experiments. Taking together all these analysis, 227 differential spots were detected from which 151 proteins were successfully identified by mass spectrometry, according to the criteria described in the methods section (Table 1 supp. info). Since 2-DE analysis is likely restricted to the most abundant proteins, alterations other than those reported in this study might also participate in the development of HCC in MAT1A-/ - mice. We have found a linear correlation between the $\mathrm{Mr}$ and $\mathrm{p} I$ calculated from the sequence of the identified proteins and the experimental electrophoretic mobility of the corresponding spot, calculated from the 2DE gels (Figure 3). This finding further validates the identity of the analyzed spots. However, $\mathrm{p} I$ and $M_{\mathrm{r}}$ deviations from linearity were observed, probably resulting from postraductional modifications and abnormal protein processing as in the case of aldehyde dehydrogenase class 2, albumin and glutathione $S$-transferase Mul. The identity of these protein species (Figure 3 ) was confirmed by de novo sequencing based on the results from ESI-MS/MS analysis. According to previous genomic and proteomic studies of HCC, ${ }^{34,41-46}$ among the 151 positive identifications, most of the changes (61.3\%) were downregulated proteins, suggesting the de-differentiation of hepatocytes associated with the neoplastic transformation. ${ }^{45} \mathrm{Up}$ and down-regulated proteins were classified with GARBAN I $^{38}$ by the biological processes in which they are involved and by 
Table 2. Proteins Differentially Expressed in at Least $50 \%$ of MAT1A-/- Liver Tumors ${ }^{a}$

\begin{tabular}{|c|c|c|c|c|c|c|}
\hline & acc. no. & $M_{\mathrm{r}} / \mathrm{p} I \mathrm{Da}$ & $\begin{array}{l}\text { peptides } \\
\text { matched }\end{array}$ & $\begin{array}{l}\text { sequence } \\
\text { coverage }\end{array}$ & function & cases \\
\hline \multicolumn{7}{|c|}{ Down-Regulated Proteins } \\
\hline Methionine adenosyltransferase & Q91X83 & $43.5 / 5.8$ & 8 & 25.7 & Synthesis of AdoMet & $6 \backslash 6$ \\
\hline Carbonic anhydrase III & P16015 & $29.4 / 8.1$ & 12 & 54.82 & Reversible hydration of carbon dioxide & $6 \backslash 6$ \\
\hline 1300018L09 rik protein & Q9DBB8 & $36.3 / 6.4$ & 12 & 43.54 & Catabolism of polycyclic aromatic hydrocarbons & $5 \backslash 6$ \\
\hline Glutamine synthetase & P15105 & $42.6 / 7.3$ & 13 & 38.07 & Nitrogen homeostasis & $5 \backslash 6$ \\
\hline Selenium binding protein 2 & Q63836 & $52.6 / 6.1$ & 10 & 20.1 & Bind selenium and acetaminophen & $5 \backslash 6$ \\
\hline Adenosylhomocysteinase & P50247 & $47.5 / 6.3$ & 6 & 13.2 & Regulation of adenosylhomocysteine levels & $5 \backslash 6$ \\
\hline Antioxidant protein 2 & O08709 & $24.7 / 5.9$ & 7 & 40.35 & Involved in redox regulation of the cell & $5 \backslash 6$ \\
\hline Senescence marker protein 30 & Q64374 & $33.4 / 5.2$ & 10 & 44.81 & Calcium homeostasis & $5 \backslash 6$ \\
\hline Sorbitol dehydrogenase & Q64442 & $40.1 / 7.0$ & 20 & 52.26 & Polyol pathway of glucose metabolism & $3 \backslash 6$ \\
\hline Phenylalanine 4 hydroxylase & P16331 & $51.9 / 6.3$ & 13 & 25.38 & Catabolism of phenylalanine & $3 \backslash 6$ \\
\hline Malate dehydrogenase & P14152 & $36.3 / 6.5$ & 10 & 31.2 & Involved in the tricarboxylic acid cycle & $3 \backslash 6$ \\
\hline Arginase 1 & Q61176 & $34.8 / 6.9$ & 17 & 62.22 & Arginine degradation via the urea cycle & $3 \backslash 6$ \\
\hline Phosphoglucomutase & Q9D0F9 & $61.3 / 6.6$ & 23 & 47.41 & Breakdown and synthesis of glucose & $3 \backslash 6$ \\
\hline Ornithine aminotransferase & P29758 & $48.3 / 6.5$ & 12 & 33.03 & Control de L-ornithine levels in tissues & $3 \backslash 6$ \\
\hline Ornithine carbamoyltransferase & P00481 & $39.7 / 9.0$ & 5 & 17.51 & Arginine biosynthesis & $3 \backslash 6$ \\
\hline Non specific lipid transfer protein & P32020 & $59.1 / 7.6$ & 15 & 36.01 & carrier for fatty acyl CoAs & $3 \backslash 6$ \\
\hline Glycine N-methyltransferase & Q91WN7 & $32.4 / 7.6$ & 10 & 49.3 & Methylation of glycine by using AdoMet & $3 \backslash 6$ \\
\hline Alcohol dehydrogenase & Q9JII6 & $36.4 / 7.3$ & 17 & 63.88 & Metabolism of ethanol & $3 \backslash 6$ \\
\hline 2810435D12 rik protein & Q9CYW4 & 28.0/6.7 & 10 & 39.44 & Hydrolase activity & $3 \backslash 6$ \\
\hline \multicolumn{7}{|c|}{ Up-Regulated Proteins } \\
\hline Apolipoprotein A1 & Q00623 & $30.5 / 5.8$ & 11 & 40.5 & transport of cl & $4 \backslash 6$ \\
\hline Apolipoprotein E & P08226 & $35.8 / 5.6$ & 16 & 44.7 & binding and internalization of lipoproteins & $4 \backslash 6$ \\
\hline Albumin & P07724 & $68.7 / 6.0$ & 10 & 16.11 & Regulation of colloidal osmotic pressure of blood & $4 \backslash 6$ \\
\hline Aldehyde dehydrogenase mit. & $\mathrm{P} 47738$ & $56.5 / 8.0$ & 12 & 27.16 & Involved in ethanol utilization & $3 \backslash 6$ \\
\hline Glutathione S-transferase Mul & P10649 & $25.8 / 8.2$ & 7 & 34.1 & Detoxification of hydrophobic electrophiles & $3 \backslash 6$ \\
\hline Glutathione S-transferase P2 & P46425 & $23.4 / 8.1$ & 6 & 41.62 & Detoxification of hydrophobic electrophiles & $3 \backslash 6$ \\
\hline Heat shock cognate $71 K D$ a protein & P63017 & $70.8 / 5.4$ & 22 & 39.31 & Stress-related, chaperone & $3 \backslash 6$ \\
\hline Protein disulfide isomerase & P09103 & $57.1 / 4.8$ & 15 & 31.04 & chaperone, isomerase and redox activities & $3 \backslash 6$ \\
\hline
\end{tabular}

${ }^{a}$ Proteins already altered in 1 day and 8 month old mice are indicated in italics and italics underlined, respectively.

their subcellular location, according to the Gene Ontology criteria $^{39}$ (Figures 1 and 2 of the Supporting Information). Most proteins differentially expressed were involved in response to external stimulus, cellular organization and biogenesis, metabolism, stress response, and transport (Figure 1 of the Supporting Information and Table 1 of the Supporting Information) and the subcellular components mainly altered were mitochondria, cytoeskeleton, endoplasmic reticulum, and nucleus (Figure 2 of the Supporting Information). About $50 \%$ of the proteins differentially expressed were metabolic enzymes. The high representation of metabolic enzymes among the identified proteins might be associated with their relative abundance in the liver, according with the biological activity of this organ. Most of the alterations affected carbohydrate, lipid and amino acid metabolism, a similar profile to that described in pre-malignant stages of MAT1A-/ - liver. ${ }^{30}$ However, tumors showed a significant increase in enzymes involved in purine and pyrimidine metabolism, according to the necessity of proliferative cells to synthesize nucleic acids (Figure 3 of the Supporting Information). A group of 27 proteins changed their levels in at least $50 \%$ of the MAT1A-/- inspected tumors (Table 2) and, according to this criteria, were selected as potential HCC-associated proteins. Among them, 19 were down-regulated (Figure 4) whereas the other 8 were upregulated species, as deduced from 2-DE gel analysis (Figure 5). The up-regulated proteins were not detected in WT 2-DE gels and gel spots of four of them (Serum albumin precursor, $42 \mathrm{kDa}$; protein disulfide isomerase, $42 \mathrm{kDa}$; aldehyde dehydrogenase mitochondrial, $36 \mathrm{kDa}$; glutathione $\mathrm{S}$ transferase $\mathrm{Mu} 1,16 \mathrm{kDa}$ ) showed deviations from the expected $\mathrm{p} I$ or $M_{\mathrm{r}}$ (Figure 5B), suggesting that the origin of these tumor-specific species relates with postranslational events more likely than involving changes of protein abundance as we previously demonstrated in the case of Apo AI. ${ }^{47}$ Heat shock cognate 71 KDa protein is located in a zone with heavy streaking, therefore, its up regulation has been further confirmed in MAT1A-/ - liver by Western blot analysis (data not shown). Interestingly, some of these alterations were identified months before the development of HCC in the liver of MAT1A-/- mice (Table 2). Downregulation of MAT, the knocked-out gene, selenium binding protein and antioxidant protein 2 were already detected in liver samples of 1 day old KO mice and, additionally, a decrease in carbonic anhydrase III, sorbitol dehydrogenase, malate dehydrogenase, arginase 1, ornithine aminotransferase, Glycine- $N$ methyltransferase, and alcohol dehydrogenase were assessed in KO livers from 8 month old mice. Therefore, these proteins might be considered as early markers of HCC in MAT1A-/mice.

Gene Expression Analysis in Human HCC. To investigate whether the 27 proteins commonly altered in MAT1A-/- mice were also associated with human HCC the expression levels of the corresponding genes was measured by RT-PCR in tumors from patients who developed HCC. Depletion of MAT1A and GNMT genes in human hepatocarcinogenesis has been demonstrated in previous studies. ${ }^{48}$ 1300018L09 Rik and 280435D12 Rik proteins were not included initially in the analysis since their biological function has not been clearly established to date. The amount of transcripts was expressed as the relative difference with respect to a control gene, histone H3F3A $\left(2^{\Delta \mathrm{Ct}}\right.$, were $\Delta \mathrm{Ct}$ represents the differential number of cycles between the target and the control gene). ${ }^{40}$ In all PCR experiments, the expression level of these genes was measured in a cDNA pool obtained from 5 transformed human cell lines (HepG2, Hep3B, Huh7, PLC, and SKHep1) (not shown). The expression levels of the 23 genes were always below $20 \%$ of those found in control liver. RT-PCR analysis revealed down-regulation of 13 


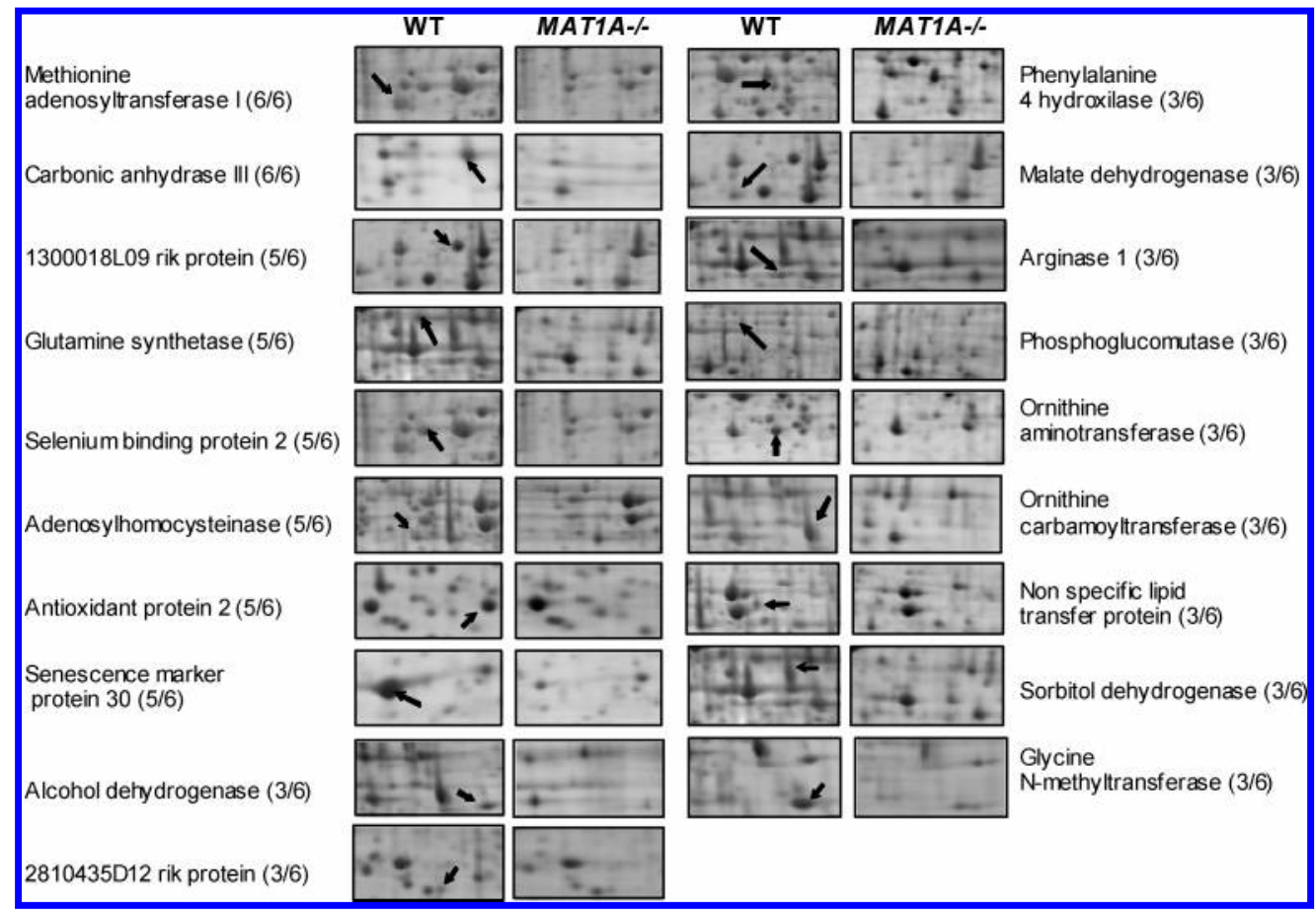

Figure 4. 2-DE sections illustrating the down-regulated protein species in at least $50 \%$ of the analyzed MAT1A-/- tumors.

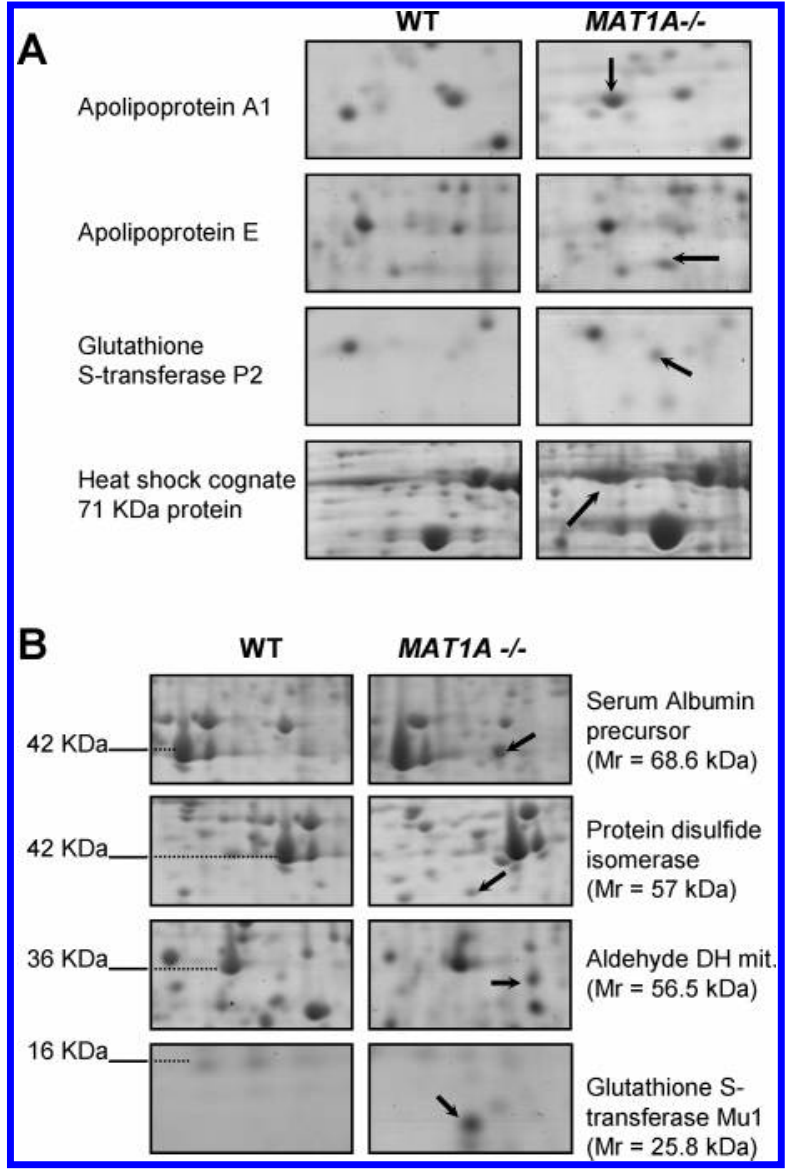

Figure 5. 2-DE sections illustrating the up-regulated protein species in at least $50 \%$ of MAT1A-/- tumors. Gel spots corresponding to protein species with the expected $M_{\mathrm{r}}(\mathrm{A})$ or with $M_{\mathrm{r}}$ values lower than those deduced from the amino acid sequence (B) are shown. The $M_{\mathrm{r}}$ of reference proteins is indicated on the left part of panel $B$. genes in human HCC samples: alcohol dehydrogenase, antioxidant protein 2, senescence marker protein 30, nonspecific lipid transfer protein, sorbitol dehydrogenase, albumin, phosphoglucomutase, phenylalanine 4 hydroxylase, apolipoprotein A1, carbonic anhydrase III, aldehyde dehydrogenase class 2, ornithine aminotransferase, and ornithine carbamoyltransferase (Figure 6). Two of them (aldehyde dehydrogenase and apolipoprotein A1) vary in the opposite way as compared to mice likely due to proteolytic cleavage (Figure $5 \mathrm{~B}$ ) and postraductional modifications respectively. ${ }^{47}$ To determine whether, in parallel with the results found in MAT1A-/- mice, these alterations also occur in premalignant states, the expression levels of the 13 positive genes was investigated in liver samples from patients with alcoholic or viral cirrhosis who had not developed HCC at the time of the study. The expression levels of alcohol dehydrogenase, antioxidant protein 2 , senescence marker protein 30, nonspecific lipid transfer protein, sorbitol dehydrogenase, albumin, and phosphoglucomutase, were significantly reduced with respect to those measured in control samples from healthy individuals (Figure 6). These changes were also detected in peritumoral tissue samples from cirrhotic patients. Cirrhotic patients displayed the same gene expression profile independently on whether they had developed malignant lesions or not and, consequently, were clustered into the same group. Notably, although differences were not statistically significant, the expression levels tended to be lower in samples from patients with alcoholic cirrhosis than in patients with viral cirrhosis and in the last group, higher levels were measured in samples from patients who had not developed HCC. Finally, the mRNA abundance of the 13 potential markers was measured in peritumoral samples from HCC patients who had not developed liver fibrosis. In all cases, the only alteration statistically significant was the down-regulation of alcohol dehydrogenase. Therefore, the cluster of 13 genes proposed here might be of help in the prognosis of patients at risk to develop HCC. 


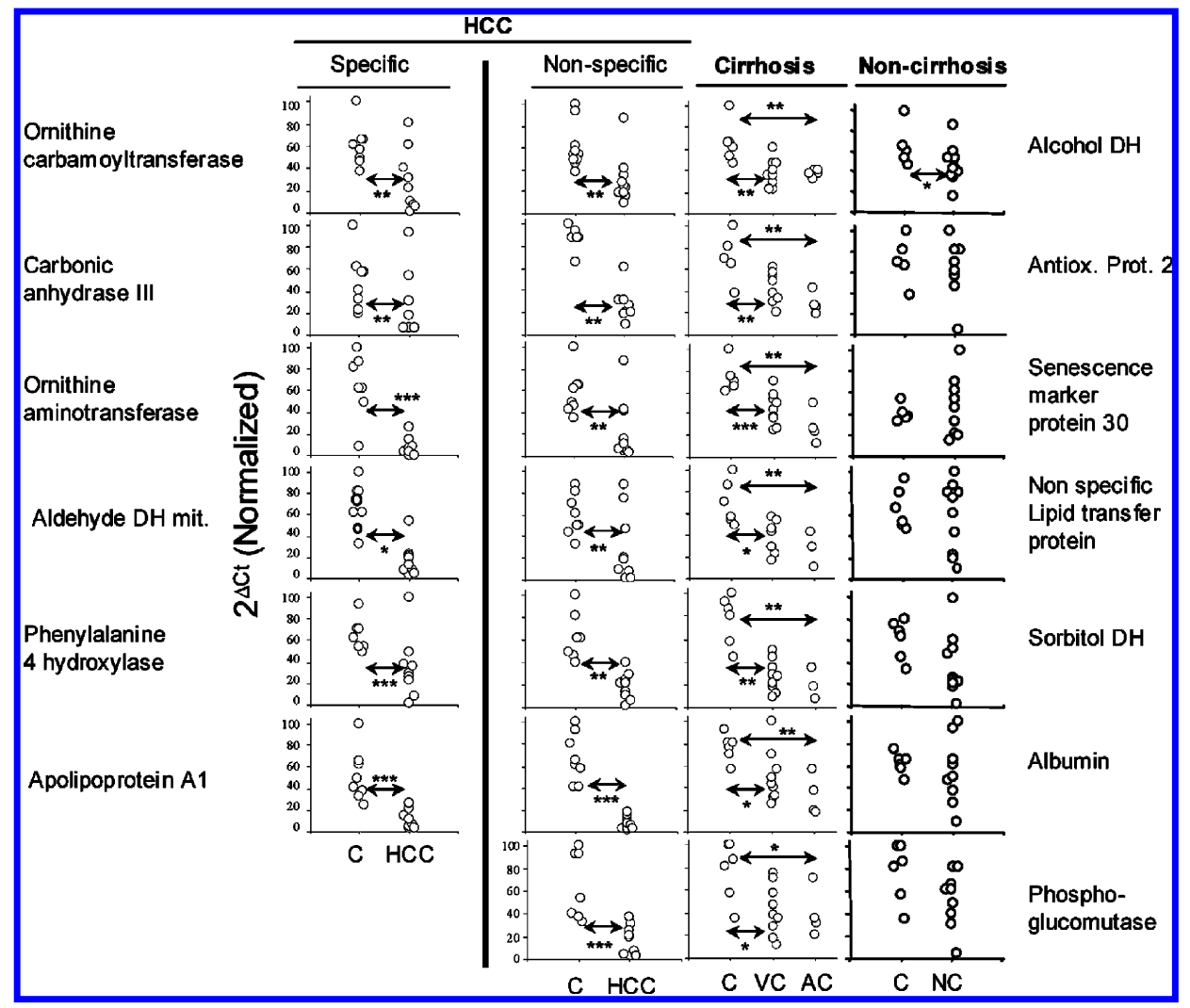

Figure 6. Expression levels of hallmark genes associated with human HCC. Down regulation of 13 genes in human HCC samples (HCC) as compared with healthy individuals (C) was revealed by RT-PCR analysis. The expression levels of these genes was also investigated in liver samples from patients with alcoholic (AC) or viral chirrosis (VC) and in peritumoral samples form HCC patients who had not developed liver fibrosis (NC). Among them, 6 alterations were specific from HCC (specific), while the other 7 were common to preneoplastic conditions such as cirrhosis (nonspecific). Statistical significance is indicated as follows: $* p<0.05, * * p<0.01, * * *$ $p<0.001$.

\section{Discussion}

AdoMet has been generally considered as a central intermediary metabolite involved in the synthesis of homocysteine and polyamines as well as is the main cellular methyl group donor. ${ }^{1}$ However, recent evidences indicate that in addition to its central metabolic function, AdoMet is in the liver an intracellular control switch that regulates essential hepatocyte's functions such as proliferation, differentiation and death. ${ }^{17}$ According to this, a deficiency of hepatic AdoMet synthesis has been associated with the progression of liver diseases. ${ }^{48-52}$ To better understand the mechanisms by which these nontraditional functions of AdoMet take place, and the mechanisms by which a chronic deficiency of this molecule in the liver participates in the progression of HCC we have attempted a comprehensive analysis of proteins associated with hepatocarcinogenesis in MAT1A-/ - mice using a combination of twodimensional electrophoresis (2-DE) and mass spectrometry to then apply the resulting information to identify hallmarks of HCC in humans.

Even though the main risk factors associated to the development of HCC are known (hepatitis C and B viruses, aflatoxin ingestion, abusive consumption of alcohol and genetic factors), the traditional diagnostic methods are far from ensuring an early detection of the disease and consequently the prognosis of the patients at the time of diagnosis is poor. ${ }^{53}$ Different genomic studies devoted to define the molecular pathogenesis of HCC resulted in dissimilar profiles of up- and downregulated genes ${ }^{41,54-56}$ These differences might result from the distinct ethiology and differentiation state of the analyzed tumors and suggest that diverse, and perhaps redundant, mechanisms are involved in the control of cell proliferation protecting cells from neoplastic transformation. This is compatible with the notion that the tumor may progress through different pathways resulting in the molecular heterogeneity denoted by genomic studies. According to this idea, the proteomic profiles of different MAT1A-/- tumors showed higher variability values than those found in controls or other preneoplastic pathological conditions associated to this model. The stochastic accumulation of errors in the biological program of cellular systems during the development of tumors ${ }^{57}$ may explain the 3 -fold increase in the proteomic variability of tumors excised from the same liver. However, proteomic heterogeneity was increased up to 10-fold when lesions from different mice were compared, suggesting that individualspecific factors may impose a selective pressure on preneoplastic foci conditioning their evolution according to a Darwinian selection system. ${ }^{57}$

Comparison of WT liver and MAT1A-/- tumor protein profiles allowed the identification of 151 distinct peptidic species that might be considered as a proteomic fingerprint of HCC in this model and provide a molecular support to representative alterations of dedifferentiated hepatocytes. In agreement with previous studies describing changes in the levels and physichochemical properties of protein species concomitantly with the progression of HCC, $41,54,56,58,59$ deviations from the expected $M_{\mathrm{r}}$ and $\mathrm{p} I$ according to the sequence of the 
identified proteins have been detected. Most likely, these abnormal species result from specific posttranslational modifications, alternative splicing or atypical proteolytic events, ${ }^{58}$ as in the case of AOP2, ${ }^{60} \mathrm{GST}^{61}$ and albumin. ${ }^{62}$ Most of the alterations (61.3\%) corresponded to down-regulated proteins in tumor nodules, likely resulting from the progressive dedifferentiation of hepatocytes during the transformation process. ${ }^{45}$ The functional clustering of all differential proteins indicates an impaired metabolic activity as well as an increased response to stress, and a deficient mitochondrial function in tumors. This functional phenotype might represent the adaptation of hepatocytes to the pressure imposed by the deficiency of AdoMet in MAT1A-/- livers..$^{28,29}$ Interestingly, these functional alterations have been commonly reported in most proteomic and genomic studies of HCC, including human samples. Since methionine metabolism, including the AdoMet synthetic reaction, is severely impaired in transformed hepatocytes, ${ }^{23-27}$ these alterations might not be restricted to our experimental model but, alternatively, they might represent, in general, the functional profile of HCC. However, it is still obscure whether these changes participate in the pathogenesis of HCC or if they are only manifestations of the disease. Metabolic disturbances and mitochondrial failure have been proposed as taking part in the progression of various types of cancer. ${ }^{63,64}$ Additionally, these alterations occur in MAT1A-/- liver months before any manifestation of liver disease could be detected by histological examination, ${ }^{30}$ suggesting their participation in the development of this HCC.

Differential proteomics has been recently applied to the study of HCC resulting in panels of altered proteins that are proposed as markers with central roles in the progression of the disease in some cases. ${ }^{34,42-46,62,65-67}$ However, the protein repertoires reported in these studies are barely coincident and, consequently, their value as biomarkers of HCC is limited. The discrepancies may arise from the experimental approach used in each study, and from the specific biological properties of the analyzed samples. This observation highlights the necessity of establishing international rules for standarization at both the analytical and diagnostic levels, to ensure obtaining of comparable and reproducible results. Additionally, the use of experimental models of hepatocarcinogenesis in which the genetic background and the environmental conditions have little impact on proteome variability, and that also facilitate the design of longitudinal studies from preneoplastic stages, may have a decisive impact in the identification of HCC associated proteins. ${ }^{57}$ Among the $151 \mathrm{up}$ - and down-regulated proteins in MAT1A-/ - tumors, 27 were differentially expressed in at least $50 \%$ of the analyzed lesions and, based on this observation, were considered as potential biomarkers of HCC. Proteins previously associated with the progression of liver disease in this model, such as ATPase $\beta$ or $\mathrm{PHB}^{30}$ were not considered for further investigations since they were found to be up and down regulated respectively in only $30 \%$ of our analysis. The selected proteins reproduce the functional phenotype of tumors, including metabolic enzymes and proteins involved in detoxification and response to stress. Additionally, selenium binding protein has been previously associated with liver fibrosis ${ }^{68}$ and senescence ${ }^{69}$ supporting its association with the development of tumors. Changes in sorbitol dehydrogenase were previously used as indicative of liver damage. ${ }^{70,71}$ In particular, the decrease of this activity in tumor nodules of MAT1A-/- mice can be correlated with the reduced capacity of transformed cells to metabolize sorbitol. ${ }^{72}$ Senescence marker protein 30 is a calcium binding protein with a central role in the preservation of liver homeostasis and cellular function. ${ }^{73}$ Finally, glutamine synthase and ornithine aminotransferase are metabolic enzymes involved in glutamine metabolism. The overexpression of these enzymes, in part through the Wnt/ $\beta$-catenin pathway, has been related with liver carcinogenesis. ${ }^{74,75}$ In rodents, it has been shown that a positive glutamine synthase phenotype favored tumor growth but not all lesions display this alteration. ${ }^{75}$ Down-regulation of glutamine synthase in MAT1A-/- mice tumors might be a specific alteration of this experimental model of chronic deficiency of AdoMet in liver. Nevertheless, we cannot rule out the occurrence of posttranslational modifications resulting in a new protein species that was not detected under the experimental conditions of our analysis.

Different genomic and proteomic studies have used peritumoral tissue as a reference to detect changes on protein expression associated with HCC. ${ }^{34,41,46,56,62,65}$ This approach might conceal alterations common to peritumoral tissue and tumors, hampering the detection of proteins which levels are already modified in hepatitis or cirrhosis, conditions at risk of HCC development. ${ }^{57}$ The use of MAT1A-/- mice as a filter system previous to the analysis of human samples have demonstrated its efficacy in the identification of hallmark proteins of HCC. Proteome complexity was reduced to 27 potential biomarkers from which 15 have been validated in human HCC samples by RT PCR analysis. Noteworthy, ornithine carbamoyltransferase, ornithine aminotransferase, carbonic anhydrase III, phosphoglucomutase and sorbitol dehydrogenase, were not associated with human HCC in previous differential proteomic studies. Depletion of ornithine carbamoyltransferase, ornithine aminotransferase, aldehyde dehydrogenase mitochondrial class 2, carbonic anhydrase III, apolipoprotein $\mathrm{Al}$, and phenylalanine 4 hydroxylase, were only observed in tumors and, therefore, might be considered as indicative of neoplastic transformation. However, the changes in alcohol dehydrogenase, antioxidant protein 2, senescence marker protein 30, nonspecific lipid transfer protein, sorbitol dehydrogenase, albumin, and phosphoglucomutase, together with methionine adenosyltransferase and glycine- $N$-methyltransferase $^{48}$ were detected in cirrhotic liver independently on whether the analyzed tissue were associated to a tumor or not. Since cirrhosis is considered at high risk for HCC development, these alterations might be considered as early markers that may contribute to the molecular definition of preneoplastic states. Interestingly, the levels of these proteins in nonfibrotic peritumoral tissue were found to be similar to those found in control individuals with the only exception of alcohol dehydrogenase that has been previously associated with liver diseases of diverse ethiology. ${ }^{76}$ Finally, although results were not statistically significant, Hsp71 cognate was increased in $40 \%$ of the analyzed tumors, a similar proportion to that found previously, ${ }^{77}$ and the results obtained for glutamine synthase are compatible with studies showing that only certain HCC human tumors are positive for this protein, ${ }^{78-80}$ although glutamine is essential to promote tumor growth. ${ }^{81}$

In summary, we have investigated in the present work the molecular mechanisms associated with the progression of HCC under a chronic deficiency of AdoMet in the liver. Proteomic analysis of MAT1A-/- tumors revealed the existence of individualspecific factors that might condition the development of preneoplastic lesions. Additionally, of the 27 proteins differentially expressed in at least $50 \%$ of the analyzed tumors, 15 
were confirmed in human samples and some of them were already altered in preneoplastic alterations. Among them, 15 were validated as markers of human HCC, and 7 were shown to be altered in premalignant pathological conditions. Our results in combination with other classical diagnostic methods, might help to the early detection of HCC.

Acknowledgment. The technical assistance of Carmen Miqueo and Maite Barbarin is acknowledged. The agreement between FIMA and the "UTE project CIMA"; Grants Plan Nacional I+D+I 2004-03538 and 2004-01855 from Ministerio de Educación y Ciencia to M.A.A. and F.J.C.; Grant ROI AA12677 from the National Institute on Alcohol Abuse and Alcoholism to S.L., M.A.A. and J.M.M.; Grant R01 AT1576 from the National Center for Complementary and Alternative Medicine to S.L., M.A.A., F.J.C., and J.M.M.; Grant R01 AA013847 from the National Institute on Alcohol Abuse and Alcoholism to S.L., J.M.M., and F.J.C.; Grants C03/02 and G03/015 from Instituto de Salud Carlos III to J.P., C.B., JC, J.M.M., F.J.C., and M.A.A.; Grants FIS PI040819 and CP04/00123 from Ministerio de Sanidad y Consumo to C.B. and M.A.A., respectively. Grant Ortiz de Landazuri from Gobierno de Navarra to C.B. and M.A.A.; Grant STREP FP6-2004-LIFESCIHEALTH-5 018649 from the $6^{\text {th }}$ framework program of the UE to F.J.C.; Grant PROFIT FIT-340000-2005-353 from Ministerio de Industria, Turismo y Comercio to F.J.C. Grants FIS PI051098 from Instituto de Salud Carlos III to J.P. and M.A.A. This laboratory is member of the National Institute of Proteomics Facilities, ProteoRed.

Supporting Information Available: This information includes a complete list of differential proteins identified in HCC from MAT1A-/- mice, a scheme representing the metabolic differences identified in MAT1A-/- tumors, proteins differentially expressed in MAT1A-/- liver clustered according to biological process and subcellular location and tables containing RT-PCR data before normalization. This material is available free of charge via the Internet at http://pubs.acs.org.

\section{References}

(1) Cantoni, G. L. L. Biol. Chem. 1953, 204 (1), 403-416.

(2) Cantoni, G. L. Annu. Rev. Biochem. 1975, 44, 435-451.

(3) Mudd, S. H.; Poole, J. R. Metabolism 1975, 24 (6), 721-735.

(4) Tabor, C. W.; Tabor, H. Adv. Enzymol. Relat. Areas Mol. Biol. 1984, $56,251-282$.

(5) Kotb, M.; Mudd, S. H.; Mato, J. M.; Geller, A. M.; Kredich, N. M.; Chou, J. Y.; Cantoni, G. L. Trends Genet. 1997, 13 (2), 51-52.

(6) Alvarez, L.; Corrales, F.; Martin-Duce, A.; Mato, J. M. Biochem. J. 1993, 293 (Pt 2), 481-486.

(7) Horikawa, S.; Sasuga, J.; Shimizu, K.; Ozasa, H.; Tsukada, K. $J$. Biol. Chem. 1990, 265 (23), 13683-13686.

(8) Horikawa, S.; Tsukada, K. Biochem. Int. 1991, 25 (1), 81-90.

(9) Kotb, M.; Kredich, N. M. J. Biol. Chem. 1985, 260 (7), 3923-3930.

(10) Cabrero, C.; Puerta, J.; Alemany, S. Eur. J. Biochem. 1987, 170 (1-2), 299-304.

(11) Okada, G.; Teraoka, H.; Tsukada, K. Biochemistrv 1981, 20 (4), 934-940.

(12) Sullivan, D. M.; Hoffman, J. L. Biochemistry 1983, 22 (7), 16361641.

(13) Mato, J. M.; Alvarez, L.; Ortiz, P.; Pajares, M. A. Pharmacol. Ther. 1997, 73 (3), 265-280.

(14) Alvarez, L.; Asuncion, M.; Corrales, F.; Pajares, M. A.; Mato, J. M. FEBS Lett. 1991, 290 (1-2), 142-146.

(15) Horikawa, S.; Ishikawa, M.; Ozasa, H.; Tsukada, K. Eur. J. Biochem. 1989, 184 (3), 497-501.

(16) Tsukada, K.; Okada, G. Biochem Biophys Res Commun 1980, 94 (4), 1078-1082.

(17) Mato, J. M.; Corrales, F. J.; Lu, S. C.; Avila, M. A. FasebJ 2002, 16 (1), $15-26$.

(18) Lu, S. C.; Gukovsky, I.; Lugea, A.; Reyes, C. N.; Huang, Z. Z.; Chen, L.; Mato, J. M.; Bottiglieri, T.; Pandol, S. J. Faseb J 2003, 17 (1), $56-58$.
(19) Gil, B.; Casado, M.; Pajares, M. A.; Bosca, L.; Mato, J. M.; MartinSanz, P.; Alvarez, L. Hepatology 1996, 24 (4), 876-881.

(20) Horikawa, S.; Ozasa, H.; Ota, K.; Tsukada, K. FEBS Lett 1993, 330 (3), 307-311.

(21) Avila, M. A.; Carretero, M. V.; Rodriguez, E. N.; Mato, J. M. Gastroenterology 1998, 114 (2), 364-371.

(22) Mato, J. M.; Camara, J.; Fernandez de Paz, J.; Caballeria, L.; Coll, S.; Caballero, A.; Garcia-Buey, L.; Beltran, J.; Benita, V.; Caballeria, J.; Sola, R.; Moreno-Otero, R.; Barrao, F.; Martin-Duce, A.; Correa, J. A.; Pares, A.; Barrao, E.; Garcia-Magaz, I.; Puerta, J. L.; Moreno, J.; Boissard, G.; Ortiz, P.; Rodes, J. J. Hepatol. 1999, 30 (6), 10811089.

(23) Huang, Z. Z.; Mato, J. M.; Kanel, G.; Lu, S. C. Hepatology 1999, 29 (5), $1471-1478$.

(24) Latasa, M. U.; Boukaba, A.; Garcia-Trevijano, E. R.; Torres, L.; Rodriguez, J. L.; Caballeria, J.; Lu, S. C.; Lopez-Rodas, G.; Franco, L.; Mato, J. M.; Avila, M. A. Faseb J 2001, 15 (7), 1248-1250.

(25) Cai, J.; Mao, Z.; Hwang, J. J.; Lu, S. C. Cancer Res 1998, 58 (7), 1444-1450.

(26) Cai, J.; Sun, W. M.; Hwang, J. J.; Stain, S. C.; Lu, S. C. Hepatology 1996, 24 (5), 1090-1097.

(27) Garcia-Trevijano, E. R.; Latasa, M. U.; Carretero, M. V.; Berasain, C.; Mato, J. M.; Avila, M. A. Faseb J 2000, 14 (15), 2511-2518.

(28) Lu, S. C.; Alvarez, L.; Huang, Z. Z.; Chen, L.; An, W.; Corrales, F. J.; Avila, M. A.; Kanel, G.; Mato, J. M. Proc. Natl. Acad. Sci. U.S.A. 2001, 98 (10), 5560-5565.

(29) Martinez-Chantar, M. L.; Corrales, F. J.; Martinez-Cruz, L. A.; Garcia-Trevijano, E. R.; Huang, Z. Z.; Chen, L.; Kanel, G.; Avila, M. A.; Mato, J. M.; Lu, S. C. Faseb J. 2002, 16 (10), 1292-1294.

(30) Santamaria, E.; Avila, M. A.; Latasa, M. U.; Rubio, A.; MartinDuce, A.; Lu, S. C.; Mato, J. M.; Corrales, F. J. Proc. Natl. Acad. Sci. U.S.A. 2003, 100 (6), 3065-3070.

(31) Parkin, D. M.; Bray, F.; Ferlay, J.; Pisani, P. Int. J. Cancer 2001, 94 (2), 153-156.

(32) Bosch, F. X.; Ribes, J.; Borras, J. Semin Liver Dis 1999, 19 (3), $271-$ 285.

(33) Llovet, J. M.; Burroughs, A.; Bruix, J. Lancet 2003, 362 (9399), 1907-1917.

(34) Li, C.; Tan, Y. X.; Zhou, H.; Ding, S. J.; Li, S. J.; Ma, D. J.; Man, X. B.; Hong, Y.; Zhang, L.; Li, L.; Xia, Q. C.; Wu, J. R.; Wang, H. Y.; Zeng, R. Proteomics 2005, 5 (4), 1125-1139.

(35) Hanash, S. M.; Madoz-Gurpide, J.; Misek, D. E. Leukemia 2002 , 16 (4), 478-485.

(36) Jungblut, P. R.; Grabher, G.; Stoffler, G. Electrophoresis 1999, 20 (18), 3611-3622.

(37) Srinivas, P. R.; Srivastava, S.; Hanash, S.; Wright, G. L., Jr. Clin. Chem. 2001, 47 (10), 1901-1911.

(38) Segura, V.; Podhorski, A.; Guruceaga, E.; Sevilla Campo, J. Corrales, F.; Rubio, A. Proteomics, accepted for publication 2005.

(39) Ashburner, M.; Ball, C. A.; Blake, J. A.; Botstein, D.; Butler, H.; Cherry, J. M.; Davis, A. P.; Dolinski, K.; Dwight, S. S.; Eppig, J. T.; Harris, M. A.; Hill, D. P.; Issel-Tarver, L.; Kasarskis, A.; Lewis, S.; Matese, J. C.; Richardson, J. E.; Ringwald, M.; Rubin, G. M.; Sherlock, G. Nat. Genet. 2000, 25 (1), 25-29.

(40) Livak, K. J.; Schmittgen, T. D. Methods 2001, 25 (4), 402-408.

(41) Kim, J. W.; Ye, Q.; Forgues, M.; Chen, Y.; Budhu, A.; Sime, J.; Hofseth, L. J.; Kaul, R.; Wang, X. W. Hepatology 2004, 39 (2), 518527.

(42) Kim, W.; Oe Lim, S.; Kim, J. S.; Ryu, Y. H.; Byeon, J. Y.; Kim, H. J.; Kim, Y. I.; Heo, J. S.; Park, Y. M.; Jung, G. Clin. Cancer Res. 2003 , 9 (15), 5493-5500.

(43) Kuramitsu, Y.; Nakamura, K. Expert Rev. Proteomics 2005, 2 (4), 589-601.

(44) Li, C.; Hong, Y.; Tan, Y. X.; Zhou, H.; Ai, J. H.; Li, S. J.; Zhang, L.; Xia, Q. C.; Wu, J. R.; Wang, H. Y.; Zeng, R. Mol. Cell Proteomics 2004, 3 (4), 399-409.

(45) Liang, C. R.; Leow, C. K.; Neo, J. C.; Tan, G. S.; Lo, S. L.; Lim, J. W.; Seow, T. K.; Lai, P. B.; Chung, M. C. Proteomics 2005, 5 (8), 2258-2271.

(46) Lim, S. O.; Park, S. J.; Kim, W.; Park, S. G.; Kim, H. J.; Kim, Y. I.; Sohn, T. S.; Noh, J. H.; Jung, G. Biochem. Biophys. Res. Commun. 2002, 291 (4), 1031-1037.

(47) Fernandez-Irigoyen, J.; Santamaria, E.; Sesma, L.; Munoz, J.; Riezu, J. I.; Caballeria, J.; Lu, S. C.; Prieto, J.; Mato, J. M.; Avila, M. A.; Corrales, F. J. Proteomics 2005, 5 (18), 4964-4972.

(48) Avila, M. A.; Berasain, C.; Torres, L.; Martin-Duce, A.; Corrales, F. J.; Yang, H.; Prieto, J.; Lu, S. C.; Caballeria, J.; Rodes, J.; Mato, J. M. L. Hepatol. 2000, 33 (6), 907-914.

(49) Cabrero, C.; Duce, A. M.; Ortiz, P.; Alemany, S.; Mato, J. M. Hepatology 1988, 8 (6), 1530-1534. 
(50) Duce, A. M.; Ortiz, P.; Cabrero, C.; Mato, J. M. Hepatology 1988 , $8(1), 65-68$.

(51) Gaull, G. E.; Tallan, H. H.; Lonsdale, D.; Przyrembel, H.; Schaffner F.; von Bassewitz, D. B. L. Pediatr. 1981, 98 (5), 734-741.

(52) Marchesini, G.; Bugianesi, E.; Bianchi, G.; Fabbri, A.; Marchi, E.; Zoli, M.; Pisi, E. Hepatology 1992, 16 (1), 149-155.

(53) Marrero, J. A.; Lok, A. S. Gastroenterology 2004, 127 (5 Suppl 1), S113-119.

(54) Lee, J. S.; Chu, I. S.; Heo, J.; Calvisi, D. F.; Sun, Z.; Roskams, T.; Durnez, A.; Demetris, A. J.; Thorgeirsson, S. S. Hepatology 2004 40 (3), 667-676.

(55) Paradis, V.; Bieche, I.; Dargere, D.; Laurendeau, I.; Laurent, C.; Bioulac Sage, P.; Degott, C.; Belghiti, J.; Vidaud, M.; Bedossa, P. Am. J. Pathol. 2003, 163 (2), 733-741.

(56) Xu, X. R.; Huang, J.; Xu, Z. G.; Qian, B. Z.; Zhu, Z. D.; Yan, Q.; Cai, T.; Zhang, X.; Xiao, H. S.; Qu, J.; Liu, F.; Huang, Q. H.; Cheng, Z. H.; Li, N. G.; Du, J. J.; Hu, W.; Shen, K. T.; Lu, G.; Fu, G.; Zhong, M.; Xu, S. H.; Gu, W. Y.; Huang, W.; Zhao, X. T.; Hu, G. X.; Gu, J. R.; Chen, Z.; Han, Z. G. Proc. Natl. Acad. Sci. U.S.A. 2001, 98 (26), 15089-15094.

(57) Thorgeirsson, S. S.; Grisham, J. W. Nat. Genet 2002, 31 (4), 339346 .

(58) Chignard, N.; Beretta, L. Gastroenterology 2004, 127 (5 Suppl 1), S120-125.

(59) Feitelson, M. A.; Sun, B.; Satiroglu Tufan, N. L.; Liu, J.; Pan, J.; Lian, Z. Oncogene 2002, 21 (16), 2593-2604.

(60) Rabilloud, T.; Heller, M.; Gasnier, F.; Luche, S.; Rey, C.; Aebersold, R.; Benahmed, M.; Louisot, P.; Lunardi, J. L. Biol. Chem. 2002, 277 (22), 19396-19401.

(61) Hayes, J. D.; Flanagan, J. U.; Jowsey, I. R. Annu. Rev. Pharmacol. Toxicol. 2005, 45, 51-88.

(62) Yokoyama, Y.; Kuramitsu, Y.; Takashima, M.; Iizuka, N.; Toda, T.; Terai, S.; Sakaida, I.; Oka, M.; Nakamura, K.; Okita, K. Proteomics 2004, 4 (7), 2111-2116.

(63) Cuezva, J. M.; Krajewska, M.; de Heredia, M. L.; Krajewski, S. Santamaria, G.; Kim, H.; Zapata, J. M.; Marusawa, H.; Chamorro, M.; Reed, J. C. Cancer Res. 2002, 62 (22), 6674-6681.

(64) Isidoro, A.; Martinez, M.; Fernandez, P. L.; Ortega, A. D.; Santamaria, G.; Chamorro, M.; Reed, J. C.; Cuezva, J. M. Biochem.J. 2004, 378 (Pt 1), 17-20.
(65) Blanc, J. F.; Lalanne, C.; Plomion, C.; Schmitter, J. M.; Bathany, K.; Gion, J. M.; Bioulac-Sage, P.; Balabaud, C.; Bonneu, M.; Rosenbaum, J. Proteomics 2005, 5 (14), 3778-3789.

(66) Kim, J.; Kim, S. H.; Lee, S. U.; Ha, G. H.; Kang, D. G.; Ha, N. Y.; Ahn, J. S.; Cho, H. Y.; Kang, S. J.; Lee, Y. J.; Hong, S. C.; Ha, W. S.; Bae, J. M.; Lee, C. W.; Kim, J. W. Electrophoresis 2002, 23 (24), 4142-4156.

(67) Paradis, V.; Degos, F.; Dargere, D.; Pham, N.; Belghiti, J.; Degott, C.; Janeau, J. L.; Bezeaud, A.; Delforge, D.; Cubizolles, M.; Laurendeau, I.; Bedossa, P. Hepatology 2005, 41 (1), 40-47.

(68) Henkel, C.; Roderfeld, M.; Weiskirchen, R.; Scheibe, B.; Matern, S.; Roeb, E. Z Gastroenterol. 2005, 43 (1), 23-29.

(69) Cho, Y. M.; Bae, S. H.; Choi, B. K.; Cho, S. Y.; Song, C. W.; Yoo, J. K.; Paik, Y. K. Proteomics 2003, 3 (10), 1883-1894.

(70) Asada, M.; Galambos, J. T. Gastroenterology 1963, 44, 578-584.

(71) Yagminas, A. P.; Villeneuve, D. C. Biochem. Med. 1977, 18 (1), $117-125$

(72) Levine, G. A.; Bissell, M. J.; Bissell, D. M. J. Biol. Chem. 1978, 253 (17), 5985-5989.

(73) Yamaguchi, M. Int. J. Mol. Med. 2005, 15 (3), 371-389.

(74) Cadoret, A.; Ovejero, C.; Terris, B.; Souil, E.; Levy, L.; Lamers, W. H.; Kitajewski, J.; Kahn, A.; Perret, C. Oncogene 2002, 21 (54), 8293-8301.

(75) Gebhardt, R.; Williams, G. M. Carcinogenesis 1995, 16 (8), 16731681

(76) Crabb, D. W. Prog. Liver Dis. 1995, 13, 151-172.

(77) Takashima, M.; Kuramitsu, Y.; Yokoyama, Y.; Iizuka, N.; Toda, T.; Sakaida, I.; Okita, K.; Oka, M.; Nakamura, K. Proteomics 2003 3 (12), 2487-2493.

(78) Christa, L.; Simon, M. T.; Flinois, J. P.; Gebhardt, R.; Brechot, C.; Lasserre, C. Gastroenterology 1994, 106 (5), 1312-1320.

(79) Miyasaka, Y.; Enomoto, N.; Nagayama, K.; Izumi, N.; Marumo, F.; Watanabe, M.; Sato, C. Br. J. Cancer 2001, 85 (2), 228-234.

(80) Osada, T.; Nagashima, I.; Tsuno, N. H.; Kitayama, J.; Nagawa, H. J. Hepatol. 2000, 33 (2), 247-253.

(81) Kovacevic, Z.; McGivan, J. D. Phvsiol. Rev. 1983, 63 (2), 547-605. PR050429V 